\title{
Thermal Gasification of Rice Husks from Rice Growing Areas in Mwea, Embu County, Kenya
}

\author{
Paul Njogu ${ }^{*}$, Robert Kinyua1, Purity Muthoni' ${ }^{1}$, Yusuyuki Nemoto² \\ ${ }^{1}$ Institute of Energy and Environmental Technology, Jomo Kenyatta University of Agriculture and Technology, \\ Nairobi, Kenya \\ ${ }^{2}$ Division of Renewable Energy and Environment, Ashikaga Institute of Technology, Ashikaga, Japan \\ Email: ${ }^{*}$ njogupaul@jkuat.ac.ke, ${ }^{*}$ njogupl@yahoo.com
}

Received 5 February 2015; accepted 23 May 2015; published 26 May 2015

Copyright (C) 2015 by authors and Scientific Research Publishing Inc.

This work is licensed under the Creative Commons Attribution International License (CC BY). http://creativecommons.org/licenses/by/4.0/

(c) $\underset{\mathrm{EY}}{\mathrm{EY}}$ Open Access

\section{Abstract}

Thermal gasification of biomass provides a potential renewable energy resource in rural areas in Kenya. Rice husks are a key byproduct of rice production that are not considered of economic value to millers. Rice husks obtained from Mwea, Embu County, Kenya were converted into syngas using a locally assembled modified updraft gasifier. The syngas production was produced at temperatures between $450^{\circ} \mathrm{C}$ and $750^{\circ} \mathrm{C}$ with injection of limited supply of air and purified using series of gas cleaning and cooling devices. Proximate analysis shows that rice husks have a mean content of $21.9 \% \pm 0.3 \%$ ash, $9.5 \% \pm 3.3 \%$ moisture, $78.8 \% \pm 0.3 \%$ volatiles and $91.8 \% \pm 1.3 \%$ total solids. Carbonized rice husks have mean contents of $37.8 \% \pm 1.2 \%$ ash, $3.1 \% \pm 0.4 \%$ moisture, $62.3 \% \pm 1.2 \%$ volatiles and $96.5 \% \pm 0.4 \%$ total solids. The study shows that feedstock is consumed at a rate of $25-32 \mathrm{Kg} / \mathrm{Hr}$ with gas generation rate of $7.76-7.78 \mathrm{~m}^{3} / \mathrm{hr}$; this translates to a gas yield of $0.31-0.35 \mathrm{~m}^{3} / \mathrm{Kg}$. Process water was re-circulated at a rate of $2.2 \mathrm{~m}^{3} / \mathrm{hr}$ within the plant. The total electricity consumption per hour was $1.1-1.3 \mathrm{kWh}$. Carbon monoxide (CO) and temperature were monitored in the working area to assess the safety of the workers and were found to be in the range of $35-50 \mathrm{ppm}$ and $24^{\circ} \mathrm{C}-29.5^{\circ} \mathrm{C}$ respectively. The two were found to be within safe limits; however, the $\mathrm{CO}$ concentrations increased when leakages occurred. Syngas was found to be composed of $16.5 \%-17.55 \% \mathrm{CO}, 14.5 \%-16.1 \% \mathrm{CO}_{2}, 4.1 \%-4.5 \% \mathrm{H}_{2}, 6.8 \%-7.2 \% \mathrm{CH}_{4}$ and $17.9 \%$ $45.7 \% \mathrm{~N}_{2}$ among others. The gas was used for direct heating applications and to run modified petrol engines. Carbonized husks were used to make energy briquettes and partly applied to the rice growing pads to improve soil properties. The technology provides energy solutions and aids in the abatement of climate change mitigation and abatement since it provides a permanent carbon sink. The technology provides a value addition chain for rice growers.

${ }^{*}$ Corresponding author.

How to cite this paper: Njogu, P., Kinyua, R., Muthoni, P. and Nemoto, Y. (2015) Thermal Gasification of Rice Husks from Rice Growing Areas in Mwea, Embu County, Kenya. Smart Grid and Renewable Energy, 6, 113-119.

http://dx.doi.org/10.4236/sgre.2015.65010 


\section{Keywords}

\section{Carbonization, Climate Change, Gasification, Syngas}

\section{Introduction}

The demand for energy in Kenya is growing rapidly due to industrial activities which have led to the high increases in prices [1]. The consumption of fossil fuels has gone with a lot of air pollution and the climate change impacts due to increase in the emission of green house gases such as carbon dioxide and other pollutants.

Rice is grown in four areas in Kenya, namely, Mwea in Kirinyaga county, Ahero and West Kano in Kisumu county and Bunyala in Busia county [2]. Kenya's rice production has ranged between 45,000 tons and 50,000 tons per year. This generates byproducts such as rice husk and rice straw [1]. Rice husk surrounds the paddy grain. During milling of paddy, about $78 \%$ of weight is produced as rice, broken rice and bran, and the rest $22 \%$ of weight of paddy is produced as husk [1] [2]. The residues can be utilized as animal feed, soil conditioner and a renewable energy resource. The use of rice husks, however, is low due to its low density and poor nutritional value. A small proportion is carbonized in the farms and applied in the rice pads as soil conditioner.

Direct use of rice husks as an energy source is hampered by low density and low heat value. It is thus imperative to convert it into combustible gas. Rice husks contain $75 \%$ organic volatile matter and $25 \%$ ash [3]. Rice husks can be converted thermally, biologically or chemically to other usable forms of energy like methane gas, liquid fuels (ethanol) and syngas/process gas. This makes it necessary to come up with innovative ways of sustainable utilization of such wastes. The current practice is open burning which leads to transfer of pollutants from land to the atmosphere.

\subsection{Thermal-Gasification}

Thermal gasification provides one of the most promising approaches of waste to energy ( $\mathrm{W} t \mathrm{E})$ conversion for rice husks [3] [4]. It makes use of heat in oxygen deficient environments to transform biomass to combustible gas. The combustible gas can be used to power internal combustion engines coupled with electricity generators for electricity generation which can be used in off grid rural electrification in remote areas especially in areas with huge annual biomass yield.

\subsection{Process Zones in an Updraft Gasifier}

As the fuel moves down in the gasifier, it passes through various reaction zones, namely, drying, pyrolysis, oxidation and reduction as illustrated in Figure 1.

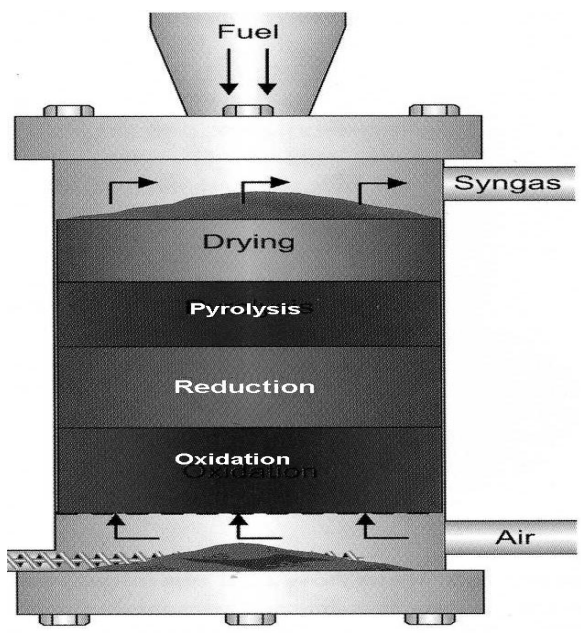

Figure 1. Gasifier reaction zones. 


\subsubsection{Drying Zone}

Here, the biomass gets dried due to heat moisture present in the fuel converts to steam:

$$
\text { Main Feedstock }+ \text { Heat } \rightarrow \text { Dry Feedstock }+\mathrm{H}_{2} \mathrm{O}_{(\mathrm{g})}
$$

\subsubsection{Pyrolysis Zone}

Pyrolysis is a thermo chemical decomposition of biomass into a range of useful products, either in the total absence of oxidizing agents or with a limited supply that does not permit gasification to an appreciable extent. It is one of several reaction steps or zones observed in a gasifier. During pyrolysis, large complex hydrocarbon molecules of biomass break down into relatively smaller and simpler molecules of gas, liquid, and char. It takes place at a temperature greater than $250^{\circ} \mathrm{C}[3]$ :

$$
\text { Main Feedstock }+ \text { Heat } \rightarrow \text { simple molecules }+\mathrm{H}_{2} \mathrm{O}_{(g)}
$$

\subsubsection{Oxidation/Combustion Zone}

An oxidation or burning zone is formed in the section where air/oxygen is supplied. These combustion reactions are highly exothermic and cause a rapid temperature increase up to $1100^{\circ} \mathrm{C}-1500^{\circ} \mathrm{C}$. The reactions are as follows [3]:

$$
\begin{array}{cc}
\mathrm{C}+\mathrm{O}_{2} \rightarrow \mathrm{CO}_{2} & +393 \mathrm{MJ} / \mathrm{kg} \cdot \text { mole } \\
2 \mathrm{H}_{2}+\mathrm{O}_{2} \rightarrow 2 \mathrm{H}_{2} \mathrm{O} & +242 \mathrm{MJ} / \mathrm{kg} \cdot \mathrm{mole}
\end{array}
$$

\subsubsection{Reaction Zone}

This is the main zone of gasifier where we get the syngas. The reactions are as follows:

$$
\begin{array}{cc}
\mathrm{C}+\mathrm{O}_{2} \rightarrow 2 \mathrm{CO} & -164.9 \mathrm{MJ} / \mathrm{kg} \cdot \mathrm{mole} \\
\mathrm{C}+\mathrm{H}_{2} \mathrm{O} \rightarrow \mathrm{CO}+2 \mathrm{H} & -122.6 \mathrm{MJ} / \mathrm{kg} \cdot \mathrm{mole} \\
\mathrm{CO}+\mathrm{H}_{2} \mathrm{O} \rightarrow \mathrm{CO}_{2}+\mathrm{H}_{2} & +42.3 \mathrm{MJ} / \mathrm{kg} \cdot \mathrm{mole} \\
\mathrm{C}+2 \mathrm{H}_{2} \rightarrow \mathrm{CH}_{4} & +75 \mathrm{MJ} / \mathrm{kg} \cdot \mathrm{mole} \\
\mathrm{CO}+3 \mathrm{H}_{2} \rightarrow \mathrm{CH}_{4}+\mathrm{H}_{2} \mathrm{O}_{(\mathrm{g})} & -205.9 \mathrm{MJ} / \mathrm{kg} \cdot \mathrm{mole}
\end{array}
$$

The mixture of gases produced in this zone is called syngas or producer gas.

\subsubsection{Advantages of Rice Husks Gasification}

Syngas production from rice husks presents one of the most promising treatments and disposal methods that incorporate energy recovery. The resultant gas can be used in direct heating applications as well as used as fuel for internal combustion engines. The carbonized husk produced has various applications which include use as activated carbon, and use as odor absorbent in animal pens; the spent husks have also been found to increase the soil conditions of agricultural soils by improving the water retention capacity. The spent husks also provide a climate mitigation opportunity due to production of biochar which presents a permanent sink for carbon [3]-[6]. The high-temperature process refines out corrosive ash elements such as chloride and potassium, allowing clean gas production [7]-[9]. The high temperatures also produce a sterilized product that can be used as a growth medium for sensitive plants such as mushrooms.

\section{Methods and Data Sources}

\subsection{Experimental Set-Up and Design}

The study was conducted at the Institute of Energy and Environmental Technology, Jomo Kenyatta University of Agriculture and Technology. Rice husks were sourced from Mwea, Embu County from Nice Rice Millers limited. The project is funded by the Japanese International Cooperation Agency through the JICA-BRIGHT project. 


\subsection{Gasifier Design and Fabrication}

An updraft gasifier was designed and fabricated with cleaning accessories and air injection systems. The gasifier was designed as described by Belonio [10]. The gasifier was made using stainless steel and mild steel sheets for inner and outside cover respectively. Temperature probes and pressure gauges were fitted to monitor operation parameters and the plant run in batch modes. The updraft gasifier is a medium size unit with a $400 \mathrm{~mm}$ internal diameter reactor with $75 \mathrm{~mm}$ gas outlet, 600 watts air blower, a $370 \mathrm{~W}$ water pump for water recirculation, pressure gauges, thermocouples and a temperature read out. The feed were converted to syngas (carbon monoxide $(\mathrm{CO})$, methane $\left(\mathrm{CH}_{4}\right)$ and hydrogen $\left(\mathrm{H}_{2}\right)$ carbon dioxide $\left(\mathrm{CO}_{2}\right)$, nitrogen $\left(\mathrm{N}_{2}\right)$ and other traces substances. The reactor has a $150 \mathrm{~mm}$ lagging to prevent heat losses and an internal perforated 3 inch pipe for gas uptake and delivery. It is fed from the top and carbonized husk removed from bottom using a screw conveyor.

\subsection{Rice Husks Analysis}

The feedstock was analyzed to determine quality for use in the gasifier. Proximate analyses were performed to determine the ash content, moisture content, total solids and volatile organic compounds. Standard methods of analysis were used in all cases [11].

\subsection{Syngas Production and Upgrading}

The feed were dried in the open to achieve moisture contents of $<12 \%$ then fed to the reactor manually. The raw gas was upgraded by passing through the gas-cleaning and cooling devices; wet scrubbers (concurrent and countercurrent spray water towers), a cyclone separator, a venturi separator, a saw dust adsorbent and a coarse and fine fabric filter.

\subsubsection{Syngas Analysis}

Syngas was analyzed for compositional analysis using gas chromatographic analyzer with a thermal conductivity detector (GC-TCD). The gas was sampled using gas sampling balloons and injected into the detector without pretreatment. Samples were run in triplicates. The peak areas were determined and the gas composition derived as percentages.

\subsubsection{Process Optimization}

The gas production was related to the gasification temperatures and air injection rate. The pressure in the system was also monitored in order to come up with the optimal operating conditions. The moisture content was also monitored and related to syngas yields.

\subsubsection{Equipment Calibration}

The air injection Blower, water pump and the gas flow meter were calibrated before use and corrections made where applicable.

\subsubsection{Combustion Emission Analysis}

Gasifier emissions were analyzed for carbon monoxide to ensure the safety of the plant workers. Workers were provided with personal protective equipments such as dust coats, helmets, dust masks and eye protection devices. The plant was also designed to allow maximum air flow to and from outdoor environment. A carbon monoxide detector meter was fitted two meters above ground to monitor ambient $\mathrm{CO}$ concentrations.

\subsubsection{Process Water Analysis}

Process water was analyzed before and after use for safe disposal. Parameters measured included temperature, total dissolved solids (TDS), conductivity, $\mathrm{pH}$ and the changes monitored.

\section{Results and Discussions}

\subsection{Rice Husk Gasifier}

The gasification system is presented in Figure 2 and Figure 3; it includes Feeder hoper, a modified updraft ga- 


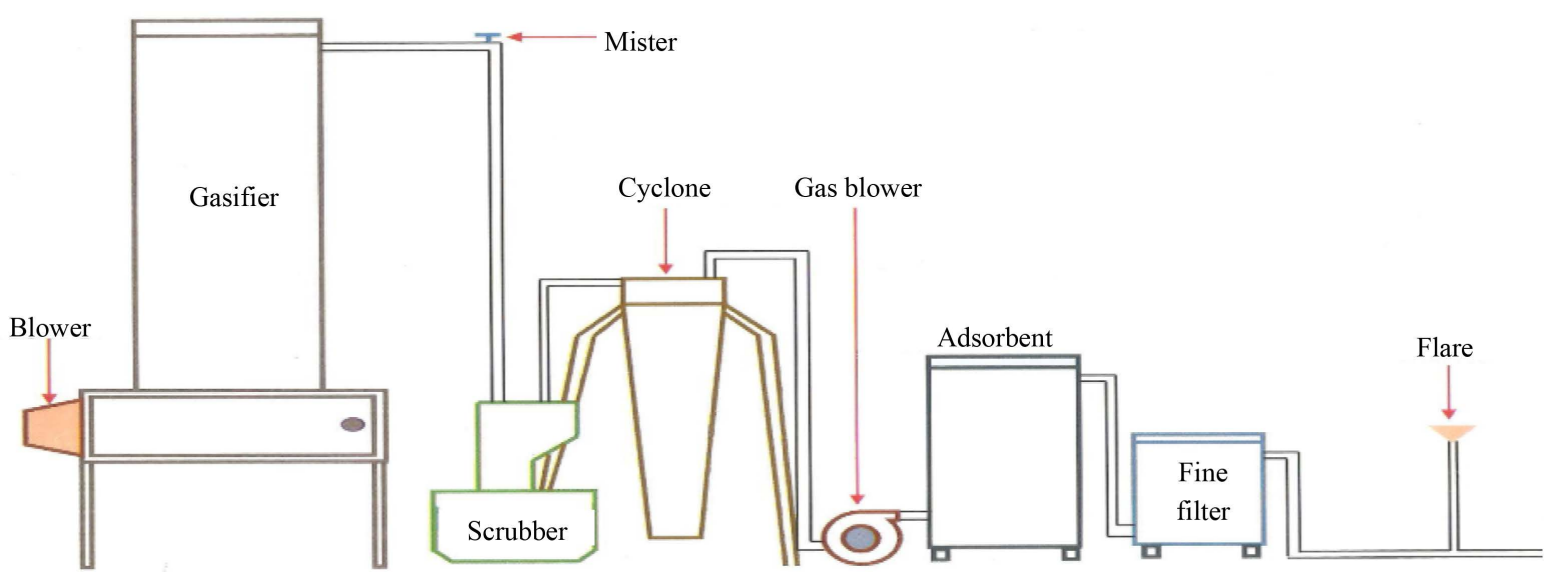

Figure 2. A Schematic for the gasification plant at JKUAT, Kenya.

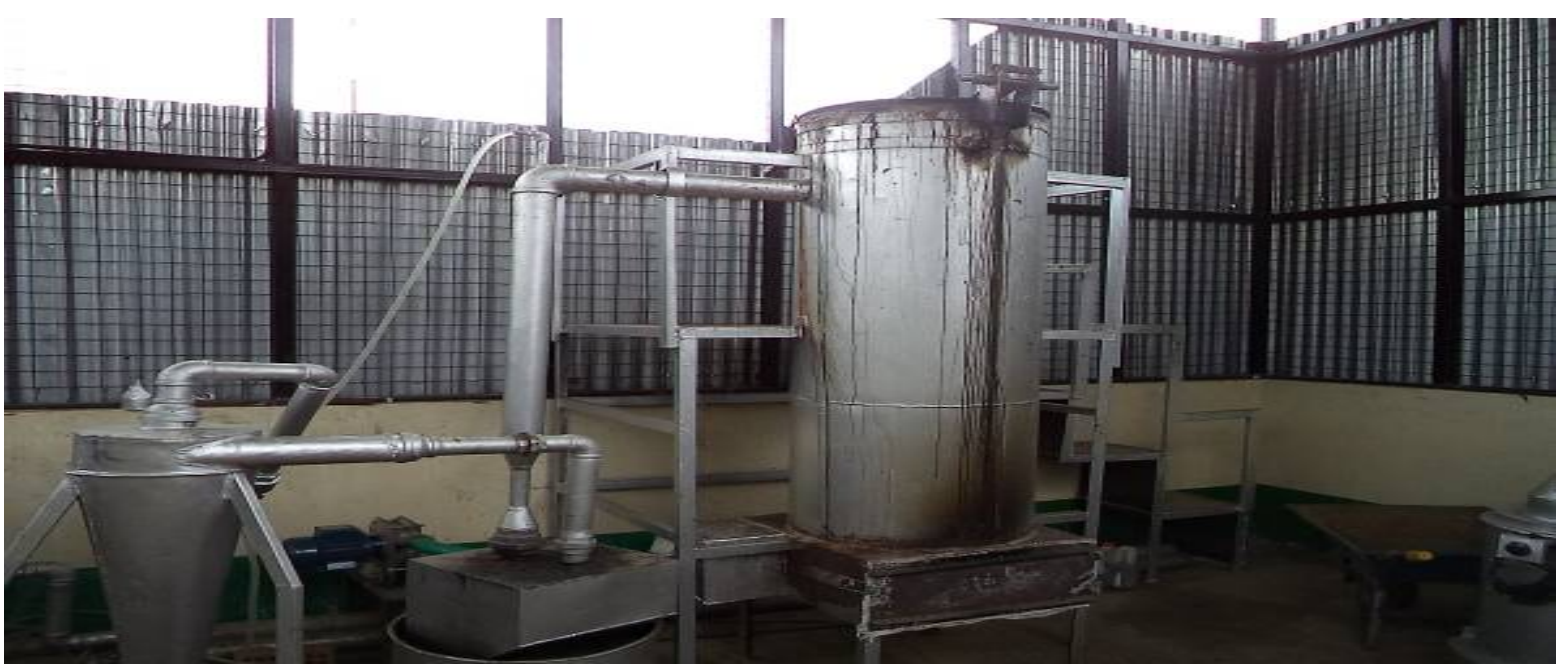

Figure 3. Gasifier in the Shed.

sifier, Cyclone separator, Air Injection port, Blower, Ash collection device, two water spray towers, A venturi scrubber, process water recirculation unit, A solid adsorbent bed, A fabric Filter, A smoke Vent, Gas transportation pipes and control valves.

\subsection{Proximate Analysis Data}

Proximate data analysis is presented in Table 1. The data shows that the husks contained high concentrations of volatiles followed by fixed carbon, moisture and ash respectively.

\subsection{Syngas Composition}

The syngas contains an approximate total of $29.2 \%$ combustible gas and the rest non combustible gases including nitrogen, carbon dioxide and others (Table 2).

\subsection{Gasifier Performance Parameters}

Gasifier performance data is presented in Table 3.

\subsection{Equipment Specifications}

Air injection Blower-Blower from Black and Decker Model KTX 5000, Power rating-600 W. Water Pump-from 
Table 1. Proximate analysis data for husks (\% Dry Wt.).

\begin{tabular}{ccccc}
\hline Component & Ash & Moisture & Volatiles & Total solids \\
\hline Raw rice husk & $21.9 \pm 0.3$ & $9.5 \pm 3.3$ & $78.8 \pm 0.7$ & $91.8 \pm 0.4$ \\
Spent husk & $37.8 \pm 1.2$ & $3.1 \pm 0.4$ & $62.3 \pm 1.2$ & $96.5 \pm 0.4$ \\
\hline
\end{tabular}

Table 2. Syngas compositional data (\%).

\begin{tabular}{ccccccc}
\hline $\mathrm{Gas}$ & $\mathrm{CO}$ & $\mathrm{H}_{2}$ & $\mathrm{CH}_{4}$ & $\mathrm{CO}_{2}$ & $\mathrm{~N}_{2}$ & Others \\
\hline$\%$ & $16.5-17.5$ & $4.1-4.5$ & $6.8-7.2$ & $14.5-16.1$ & $16.9-45.7$ & $1.24-1.4$ \\
Mean & $16.9 \pm 1.1$ & $4.2 \pm 0.5$ & $7 \pm 0.5$ & $15.1 \pm 0.5$ & $25.2 \pm 5$ & $1.4 \pm 0.3$ \\
\hline
\end{tabular}

Table 3. Performance parameters of gasification.

\begin{tabular}{cc}
\hline Parameter & Updraft gasification plant \\
\hline Volume syngas produced $\left(\mathrm{m}^{3} / \mathrm{hr}\right)$ & $7.76-7.78$ \\
Gas generation $\left(\mathrm{m}^{3} / \mathrm{ton}\right)$ & $310-350$ \\
Gasification temperature $\left({ }^{\circ} \mathrm{C}\right)$ & $450-750$ \\
Gas temperature of outlet after cleaning and cooling $\left({ }^{\circ} \mathrm{C}\right)$ & 55 \\
Consumption of biomass $(\mathrm{Kg} / \mathrm{hr})$ & $25-32$ \\
Volume of circulating water $\left(\mathrm{m}^{3} / \mathrm{hr}\right)$ & 2.2 \\
CO concentration $(\mathrm{ppm})$ & $35-50$ \\
Weight reduction per batch $(\mathrm{Kg})$ & $7.2-7.5$ \\
Temperature in working area $\left({ }^{\circ} \mathrm{C}\right)$ & $24-29.5$ \\
Ash removing manner & Scooping \\
Device of gas cleaning and cooling system & Cyclone separator, 2 spray scrubbers, 1 venturi scrubber, filter \\
\end{tabular}

Pedrollo Made in Italy Model PKM 60, Supplied by Davis and Shirtliff. Power rating-0.37 W. Gas volume Meter $\left(\mathrm{m}^{3}\right)$, maximum pressure- $10 \mathrm{kPa}$, maximum flow rate of $2.5 \mathrm{M}^{3} / \mathrm{hr}$.

\subsection{Occupational Safety Data}

The carbon monoxide concentration in the working area was monitored using a carbon monoxide (CO) detector meter Model CA895 from Chauvin Arnoux. The CO was found to be in the range of 35 - 50 ppm which is within the maximum bearable level for continuous exposure for 8 hours. However higher levels were recorded where leakage occurred. Temperature in working area was in the range of $24^{\circ} \mathrm{C}-29.5^{\circ} \mathrm{C}$ which is within safe limits for continuous exposure for 8 hours.

\subsection{Process Water Data}

Data are presented in Table 4. The $\mathrm{pH}$ decreased by $33.2 \%$ which can be attributed to the dissolution of $\mathrm{CO}_{2}$, TDS, temperature and conductivity increased by $4.2 \%, 17.2 \%$ and $4.7 \%$ respectively.

\section{Conclusion and Recommendations}

The present study shows great potential for conversion of rice husks into clean gas fuel and carbonized husks. Carbonized husks were used to make energy briquettes and partly applied to the rice growing pads to improve soil properties. The technology provides energy solutions and aids in the abatement of climate change mitigation and abatement since it provides a permanent carbon sink. The technology provides a value addition chain for rice growers. 
Table 4. Process water data.

\begin{tabular}{cccc}
\hline Parameter & Initial & After gasification & $\%$ change \\
\hline Conductivity $(\mu \mathrm{S})$ & $325 \pm 2.7$ & $341.7 \pm 4.51$ & +4.7 \\
TDS $(\mathrm{mg} / \mathrm{L})$ & $165.7 \pm 2.5$ & $172.3 \pm 3.51$ & +4.2 \\
Temperature $\left({ }^{\circ} \mathrm{C}\right)$ & $23.13 \pm 0.5$ & $27 \pm 0.53$ & +17.2 \\
$\mathrm{pH}$ & $6.83 \pm 0.3$ & $3.8 \pm 0.03$ & -33.2 \\
\hline
\end{tabular}

\section{Acknowledgements}

Authors wish to acknowledge technicians in the engineering workshops. Mwea Rice Millers limited for providing the Rice Husks. The Japan International Cooperation Agency (JICA) and JICA-BRIGHT project for the financial support.

\section{References}

[1] Government of Kenya (2009) National Rice Development Strategic Plan (2008-2018). Ministry of Agriculture, Nairobi.

[2] TARDA (2009) Tana Delta Irrigation Project.

[3] Rajvansh, A.K. (2013) Nimbkar Agricultural Research Institute, PHALTAN-415523, 1986. www.narphaltan.org

[4] Maharashtra, I., Dutta R. and Dutt, G.S. (1981) Producer Gas Engines in Villages of Less-Developed Countries. Science, 213, 731-736. http://dx.doi.org/10.1126/science.213.4509.731

[5] Kaupp, A. and Goss, J.R. (1983) Technical and Economic Problems in the Gasification of Rice Hulls. Physical and Chemical Properties. Energy in Agriculture, 1, 201-209.

[6] Kaupp, A. and Goss, J.R. (1981) State of the Art for Small Scale (to $50 \mathrm{~kW}$ ) Gas Art for Small Scale (to $50 \mathrm{~kW}$ ) Gas Producer-Engine Producer-Engine Systems. Final Report, Chap 5, U.S.D.A., Forest Service.

[7] Foley, G. and Barnard, G. (1983) Biomass Gasification in Developing Countries, Technical Report No. 1, Chap 2.4, Earthscan, London.

[8] Van Der Heijden, S., Szladow, A.J., Barabas, M. and Sirianni, G. (1981) Wood Gasification system for Electricity Production. Proceedings of 16th Intersociety Energy Conversion Engineering (16th IECEC), Atlanta, 9-14 August 1981.

[9] Stickney, R.E., Piamonte, V.N. and Belonio, A.T. (1989) Converting Rice Hull to Gaseous Fuel. Appropriate Technology, 16, 14-16.

[10] Van Der Heijden, S., Szlakow, A.J., Barabas, M. and Belonio, A.T. (2005) Rice Husk Gas Stove Handbook. Appropriate Technology Center Department of Agricultural Engineering and Environmental Management College of Agriculture Central Philippine University Iloilo.

[11] Eaton, A.D., Clesceri, L.S., Greenberg, A.E. and Franson, M.A.H. (1995) Standard Methods for the Examination of Water and Wastewater. American Public Health Association, Washington DC. 